Check for updates

Cite this: RSC Adv., 2018, 8, 3547

\title{
A selective and sensitive nanosensor for fluorescent detection of specific IgEs to purified allergens in human serum
}

\author{
Jianrong Yun, (D) a Fang Duan, (D) ${ }^{\mathrm{c}}$ Liming Liu, ${ }^{\mathrm{b}}$ Xiulai Chen, ${ }^{\mathrm{b}}$ Jia Liu, ${ }^{\mathrm{b}}$ Qiuling Luo \\ and Jing $\mathrm{Wu}(\mathrm{DD})$ *ab
}

Food allergies are increasingly recognized as a major healthcare concern. In order to sensitively and specifically detect allergies from blood samples of at-risk allergic patients, an effective magnetic fluorescence sensing platform (EMFP) was constructed. The EMFP incorporated hollow mesoporous silica nanospheres (HMNs) to amplify signal from the target lgE in addition to magnetic nanoparticles (MNPs) to capture and separate the target IgE. The application of EMFP to immunoassays indicated a detection limit of $0.0159 \mathrm{ng} \mathrm{mL}^{-1}$ for low concentration specific immunoglobulin E (slgE) against purified shellfish Metapenaeus ensis (Meta. E.) allergens, which is 15 fold more sensitive than the commercially available Food and Drug Administration-approved analyzers. Notably, EMFP was specific for the targeted slgE even with interference by other slgEs. In addition, the detection time is only $75 \mathrm{~min}$, considerably faster than current commercial ELISA kits for IgE assays. Together, these results demonstrated that EMFP has excellent sensitivity and selectivity for the rapid detection of slgE. The method thus exhibits potential toward the rapid monitoring of slgE against Meta. E. allergens in clinical application.

Received 18th September 2017

Accepted 7th January 2018

DOI: 10.1039/c7ra10377h

rsc.li/rsc-advances process is conducted in vitro, and thus does not expose patients to allergens. ${ }^{17,18}$ Third, the blood tests can serve as an alternative to skin tests for patients who suffer from severe symptoms and cannot interrupt medication. ${ }^{19}$ Furthermore, studies have revealed that the number of SIgE detected against allergens is able to predict the extent of allergy symptoms. ${ }^{\mathbf{2 0 - 2 2}}$

Several current methods are available to determine sIgEs in serum including radioimmunometric assays, commercial analyzer systems, or enzyme-linked immunosorbent assays (ELISA). ${ }^{23-26}$ Although the detection limit of the radioimmunometric assay is very low $\left(0.05 \mathrm{ng} \mathrm{mL}{ }^{-1}\right),{ }^{26}$ using radioactive reagents constitutes a serious drawback. The commercial autoanalyzer system (the ImmunoCAP ISAC assay, Phadia) employed to determine $\mathrm{sIgE}$ possesses a published lowest detection limit of only $0.24 \mathrm{ng} \mathrm{mL},{ }^{23}$ and the detection cost is usually fairly expensive for most patients. The ELISA tends to be laborious and requires highly trained personnel and numerous operation steps, thereby failing to allow the timely design of treatments to prevent allergic patients from life-threatening events. $^{\mathbf{2 4 2 5}}$ Recently, nanomaterials have increasingly been used for food allergy detection. ${ }^{27-30}$ Although the detection limit for the application of photonic crystal enhanced fluorescence toward detection of $\mathrm{SIgE}$ is very low $\left(0.048 \mathrm{ng} \mathrm{mL}{ }^{-1}\right),{ }^{30}$ the detection procedures are cumbersome, and substantial, expensive equipment is required, which limit its clinical application. Gold nanoclusters as fluorescent labels for the determination of total $\mathrm{IgE}$ is more convenient and simple,
${ }^{a}$ School of Pharmaceutical Sciences, Jiangnan University, 1800 Lihu Road, Wuxi 214122, Jiangsu Province, P. R. China. E-mail: wujing@jiangnan.edu.cn; Fax: +86510-85197873; Tel: +86-510-85197873

${ }^{b}$ The Key Laboratory of Industrial Biotechnology, Ministry of Education, Jiangnan University, Wuxi 214122, Jiangsu Province, P. R. China

${ }^{c}$ School of Chemical and Material Engineering, Jiangnan University, Wuxi 214122, Jiangsu Province, P. R. China 
however, the detection limit is $0.2 \mathrm{ng} \mathrm{mL}^{-1}$ which does not provide adequate levels of sensitivity, and the test results do not suggest which allergen may be mediating the allergic reaction. ${ }^{28}$ Therefore, there is a pressing need to develop new techniques for the rapid, low-cost, and sensitive detection of sIgEs.

Notably, the development of previous systems of sIgE detection depended on the use of crude allergen extracts from biological materials. However, it is often difficult to normalize for allergen content and isolation efficiency. ${ }^{31}$ Thus, an optimal detection method should be calibrated against purified allergens prior to testing using actual biological samples. One likely option would be shellfish, as one of the eight major food allergens responsible for most anaphylactic reactions owing to its economic and nutritional value. ${ }^{32,33}$

In order to solve the problems of low sensitivity, timerequirements, and interminable operation steps in the process of testing $\mathrm{sIgE}$, the strategies of signal amplification and rapid target enrichment were adopted in this study. We synthesized hollow mesoporous materials as an efficient strategy in signal amplification to improve sensitivity. Magnetic nanoparticles (MNPs) were synthesized to separate and enrich the target sIgE to simplify operations and allow rapid detection. Proper carbodiimide conjugation was utilized to generate fluorescent immune particles (HMNs@PDDA@PAA-anti-IgE) and magnetic immune particles $\left(\mathrm{Fe}_{3} \mathrm{O}_{4} @ \mathrm{SiO}_{2} @ \mathrm{PAA}\right.$-allergens). Integrating the two materials permitted the development of an efficient magnetic fluorescence platform (EMFP). Taking SIgE against the shellfish Metapenaeus ensis (Meta. E.) as a study model, a new and simple fluorescence sensor was developed with the characteristics of easy operation along with rapid and sensitive detection.

\section{Experimental}

\section{Chemicals and instruments}

All chemicals were purchased from Aldrich (St. Louis, MO, USA) unless otherwise stated. Tetraethoxysilane (TEOS, >99.9\%), cetyl trimethyl ammonium bromide (CTAB, $>99.0 \%$ ), polystyrene (PS, $5 \mathrm{wt} \%$ in water), iron oxide $\left(\mathrm{Fe}_{3} \mathrm{O}_{4}, 99.5 \%\right.$ metals basis), ammonium hydroxide solution ( $28 \mathrm{wt} \%$ ), and hydrochloric acid (36 wt\%), ( $N$-(3-dimethylaminopropyl)- $N$-ethyl-carbodiimide) (EDC, >99.0\%), 1-hydroxy-5-pyrrolidinedione (NHS, 98.0\%), fluorescein 5(6)-isothiocyanate (FITC, 95\%), poly dimethyl diallyl ammonium chloride (PDDA, $60 \mathrm{wt} \%$ ), polyacrylic acid (PAA, MW-2000), 4-dimethylaminopyridine (DMAP, 99.0\%), dicyclohexylcarbodiimide (DCC, 99.0\%), N,N-dimethylformamide (DMF, 98.0\%), blocking buffer (Beyotime, Shanghai, China), and Tween-20. Deionized water was generated using a Milli-Q integral pure and ultrapure water purification system (Millipore, Billerica, MA, USA). The human IgE ELISA Kit was purchased from Multi Sciences (Lian Ke) Biotech, Co., Ltd. (Hang Zhou, China).

The following equipment was used for sample characterization. Fourier transform infrared (FTIR) instrument (Bruker Vertex 70 FTIR, Karlsruhe, Germany) (400-4000 $\mathrm{cm}^{-1}$, KBr pellet technique), an X-ray diffractometer (Rigaku D/Max-Ra, Tokyo, Japan) $(\lambda=1.5418 \AA$ ) to record X-ray diffraction (XRD) curves, and sample morphology was analyzed with a transmission electron microscope (TEM) (JEOL JEM-2100, Tokyo, Japan). Vibrating sample magnetometry (VSM) (Lake Shore 7410, Houston, USA) was applied to record sample magnetic features. Emission spectra were recorded using a fluorescence spectrophotometer (Hitachi F-4500, Tokyo, Japan).

\section{Source of materials}

We evaluated the feasibility of EMFP for the sensitive and selective determination of allergen-specific IgE; the two recombinant purified major allergens tropomyosin and arginine kinase produced by Escherichia coli, and Meta. E. extract were employed. The human sera used in these studies were provided by Wuxi the Fourth People's Hospital, which were clinically tested as representing true negative and positive samples with a standard clinical analyzer used for allergy testing (ELISA).

\section{Preparation of hollow mesoporous silica nanospheres (HMNs)}

HMNs were prepared following previously established methodology with some modifications. ${ }^{34}$ Briefly, $0.30 \mathrm{~g}$ CTAB was dissolved in a mixture of $1.0 \mathrm{~mL}$ ammonium hydroxide solution, $12 \mathrm{~g}$ ethanol, and $29 \mathrm{~g}$ water. Then, $500 \mu \mathrm{L}$ of $5 \%$ PS was added dropwise to the above CTAB solution at room temperature with vigorous stirring and subsequently sonicated for $20 \mathrm{~min}$. The milky mixture was then magnetically agitated for $30 \mathrm{~min}$ before injecting $120 \mu \mathrm{L}$ of TEOS inchwise. The mixture was kept at room temperature for $24 \mathrm{~h}$ before the mesoporous silica-coated latex was harvested by centrifugation at $6000 \mathrm{~g}$ for $5 \mathrm{~min}$. The precipitate was washed with numerous copious amounts of ethanol and then dried at $45^{\circ} \mathrm{C}$. Finally the material was calcined in air at $600{ }^{\circ} \mathrm{C}$ for $5 \mathrm{~h}$ using a heating rate at $3{ }^{\circ} \mathrm{C} \min ^{-1}$ to form HMNs.

\section{Preparation of immunolabels of FHMNs@polymers-anti-IgE}

In order to obtain the immuno labels, $0.04 \mathrm{~g}$ of HMNs and $0.012 \mathrm{~g}$ of FITC were added to $5 \mathrm{~mL}$ deionized water. The mixture was stirred at room temperature for $48 \mathrm{~h}$ before centrifuging and drying the compounds at $45{ }^{\circ} \mathrm{C}$. Then, $10 \mathrm{mg}$ of FHMNs were immersed in $0.20 \%$ PDDA aqueous solution with stirring for $30 \mathrm{~min}$ to produce a homogeneous suspension. The remaining PDDA was then removed by washing with deionized water via centrifugation, and subsequently the compound was immersed in a $0.50 \%$ PAA solution with stirring for approximately $30 \mathrm{~min} .^{35}$ The remaining PAA polymer was removed by centrifuging at high speed. The obtained nanospheres were further self-assembled with PDDA and PAA by repeating the steps above. The eventual nanocomposites (FHMNs@polymers) fulfilled the necessary requirement of preserving the internal fluorescein dye molecule from leakage; this property was confirmed using ultraviolet and fluorescence spectrum analysis of the supernatant after centrifugation. The number of fluorescein molecules stored in the FHMNs@polymers was judged by testing the fluorescence intensity of the released dye molecules from $10 \mathrm{mg}$ of FHMNs. We obtained the 
same content of $37.56 \%$ from multiple acquired detections, confirming consistency.

The prepared nanospheres via layer-by-layer self-assembly were dispersed into a mixture that contained $0.5 \mathrm{mg} \mathrm{mL}$ NHS and $1 \mathrm{mg} \mathrm{mL}^{-1}$ EDC for $30 \mathrm{~min}$ to motivate the carboxyl group of the PAA layer. ${ }^{36}$ Subsequently, the nanospheres were rapidly dispersed into anti-IgE antibody $\left(\mathrm{Ab}_{2}\right)$ solution at $37{ }^{\circ} \mathrm{C}$ for $2 \mathrm{~h}$ to generate immunolabels of FHMNs@polymers. After collection by centrifugation, the precipitate was washed three times with a washing buffer (PBST) containing $10 \mathrm{mM}$ sodium phosphate, $0.15 \mathrm{M} \mathrm{NaCl}$, and $0.05 \%(\mathrm{v} / \mathrm{v})$ Tween-20 to remove the remaining antibodies. The remnant immunocompetent domains of the FHMNs@polymers-anti-IgE were blocked with blocking reagent at $37^{\circ} \mathrm{C}$ for $1 \mathrm{~h}$. Eventually, after centrifuging the nanocomposites were washed three times with washing buffer (pH 7.4) and stored in PBS (pH 7.4) at $4{ }^{\circ} \mathrm{C}$.

\section{Preparation of magnetic nanoparticles}

$\mathrm{Fe}_{3} \mathrm{O}_{4} @ \mathrm{SiO}_{2}$ nanoparticles were prepared according to a previously established method with several modifications. ${ }^{37}$ Briefly, $300 \mathrm{mg}$ of $\mathrm{Fe}_{3} \mathrm{O}_{4}$ was dispersed into a mixture of $40 \mathrm{~mL}$ ethanol and $4 \mathrm{~mL} \mathrm{H}_{2} \mathrm{O}$. After sonicating the mixture for $15 \mathrm{~min}, 5 \mathrm{~mL}$ ammonia and $2 \mathrm{~mL}$ TEOS were added while stirring. The reaction was carried out for $12 \mathrm{~h}$, after which the product was magnetically separated, washed with hydrochloric acid $\left(0.1 \mathrm{~mol} \mathrm{~L}^{-1}\right)$ and water three times, and then vacuum dried at $60{ }^{\circ} \mathrm{C}$ for 10 h. $\mathrm{Fe}_{3} \mathrm{O}_{4} @ \mathrm{SiO}_{2} @$ PAA nanospheres were prepared following a previously established procedure. Briefly, $1 \mathrm{~g}$ of $\mathrm{Fe}_{3} \mathrm{O}_{4} @ \mathrm{SiO}_{2}$ was dispersed in $33 \mathrm{~mL} \mathrm{DMF}$, and this was then mixed with a solution of $2 \mathrm{~g}$ PAA dissolved in $33 \mathrm{~mL}$ DMF. After sonication for $30 \mathrm{~min}$, the mixture was heated to $110{ }^{\circ} \mathrm{C}$ while stirring vigorously. Next, $0.033 \mathrm{~g}$ of DMAP (dissolved in $3.3 \mathrm{~mL}$ of DMF) and $0.33 \mathrm{~g}$ of DCC (dissolved in $6.6 \mathrm{~mL}$ of DMF) were added dropwise. The mixture was kept at $110^{\circ} \mathrm{C}$ for $12 \mathrm{~h}$ while stirring. The products were magnetically separated, washed with ethanol three times, and vacuum dried at $60^{\circ} \mathrm{C}$.

\section{Preparation of magnetic immune probes of $\mathrm{Fe}_{3} \mathrm{O}_{4} @ \mathrm{SiO}_{2} @ P A A-a l l e r g e n s$}

$\mathrm{Fe}_{3} \mathrm{O}_{4} @ \mathrm{SiO}_{2} @ \mathrm{PAA}$-allergens immune probes were prepared following established methodology. Briefly, $\mathrm{Fe}_{3} \mathrm{O}_{4} @ \mathrm{SiO}_{2} @ \mathrm{PAA}$ were dispersed in a solution that contained $1 \mathrm{mg} \mathrm{mL}^{-1} \mathrm{EDC}$ and $0.5 \mathrm{mg} \mathrm{mL} \mathrm{mL}^{-1} \mathrm{NHS}$ for $30 \mathrm{~min}$. After activation, the $\mathrm{Fe}_{3} \mathrm{O}_{4} @$ $\mathrm{SiO}_{2} @$ PAA was rinsed with $\mathrm{PBS}(\mathrm{pH} 7.4)$, then immediately dispersed into allergens (Ag) solution for $2 \mathrm{~h}$ to yield $\mathrm{Fe}_{3} \mathrm{O}_{4}$ @$\mathrm{SiO}_{2} @ P A A-a l l e r g e n s . \mathrm{Next}$, the composite was magnetically washed with PBS three times to remove the residual antibodies. The remaining active sites of $\mathrm{Fe}_{3} \mathrm{O}_{4} @ \mathrm{SiO}_{2} @ \mathrm{PAA}$-allergens were blocked with blocking buffer at $37{ }^{\circ} \mathrm{C}$ for $1 \mathrm{~h}$. The resulting composites were separated and washed with PBS (pH 7.4) three times and stored in $10 \mathrm{~mL}$ PBS ( $\mathrm{pH} 7.4)$ at $4{ }^{\circ} \mathrm{C}$ before use.

\section{Bioassay procedure for IgE}

The assay procedure was as follows: $0.1 \mathrm{~mL}$ of human serum or serum dilution in blocking reagent was incubated with the mixture of $0.1 \mathrm{~mL}$ of $\mathrm{Fe}_{3} \mathrm{O}_{4} @ \mathrm{SiO}_{2} @ \mathrm{PAA}$-antigens and $0.15 \mathrm{~mL}$ of
FHMNs@polymers-anti-IgE, next, the mixture was magnetically attracted after being vigorously shaken at $37^{\circ} \mathrm{C}$ for some time and the non-magnetic portions were discarded. The magnetic precipitates were carefully washed with wash buffer three times. Lastly, $3 \mathrm{~mL}$ of $0.1 \mathrm{~mol} \mathrm{~mL}{ }^{-1}$ sodium hydroxide solution (pH 11) was used to dissolve the HMNs and release the internal fluorescent dye with ultrasonic processing for $10 \mathrm{~min}$. The fluorescence intensity was determined to show the sIgE content.

\section{Results and discussion}

\section{Synthesis and characterization of materials}

The magnetic beads were utilized as allergen carriers to capture and enrich samples for testing in a one-step process. The Stöber method was used to produce $\mathrm{Fe}_{3} \mathrm{O}_{4} @ \mathrm{SiO}_{2},{ }^{37}$ with the silicon source coated on the surface of $\mathrm{Fe}_{3} \mathrm{O}_{4}$, followed by covalent binding with PAA to eventually form $\mathrm{Fe}_{3} \mathrm{O}_{4} @ \mathrm{SiO}_{2} @ P A A$. The synthesized material was characterized using TEM, FTIR, XRD, and VSM. Fig. 1A shows TEM images of $\mathrm{Fe}_{3} \mathrm{O}_{4}$ and $\mathrm{Fe}_{3} \mathrm{O}_{4} @ \mathrm{SiO}_{2}$. $\mathrm{Fe}_{3} \mathrm{O}_{4}$ exhibited angular and amorphous particles with different sizes ranging from 7 to $25 \mathrm{~nm}$. Visible aggregation of $\mathrm{Fe}_{3} \mathrm{O}_{4}$ was displayed in the TEM image that could be attributed to the strong magneticity. In comparison, $\mathrm{Fe}_{3} \mathrm{O}_{4} @ \mathrm{SiO}_{2}$ particles displayed spherical morphology with a larger average diameter of $110 \mathrm{~nm}$. The FTIR spectra of $\mathrm{Fe}_{3} \mathrm{O}_{4}, \mathrm{Fe}_{3} \mathrm{O}_{4} @ \mathrm{SiO}_{2}$, and $\mathrm{Fe}_{3} \mathrm{O}_{4} @$ @$\mathrm{SiO}_{2} @ P A A$ are shown in Fig. 1B. The bands at $1082 \mathrm{~cm}^{-1}$ and $957 \mathrm{~cm}^{-1}$ could be assigned to $\mathrm{Si}-\mathrm{O}-\mathrm{Si}$ and $\mathrm{Si}-\mathrm{OH}$ groups, ${ }^{38}$ respectively, and the peak intensity at $653 \mathrm{~cm}^{-1}$ for $\mathrm{Fe}-\mathrm{O}$ group decreased significantly (curve b). ${ }^{39}$ After adding PAA based on $\mathrm{Fe}_{3} \mathrm{O}_{4} @ \mathrm{SiO}_{2}$, primary absorptions appeared at $1379 \mathrm{~cm}^{-1}$ for $-\mathrm{OH}$ of the $\mathrm{C}-\mathrm{OH}$ group, and the peak at $1663 \mathrm{~cm}^{-1}$ of the $\mathrm{C}=\mathrm{C}$ group increased. ${ }^{40}$ Given these results, we could confirm that the silica and PAA had well-coated the outer surface of $\mathrm{Fe}_{3} \mathrm{O}_{4}$ particles. $^{\mathbf{4 0 , 4 1}}$

To examine the magnetic beads structure, the X-ray diffraction patterns for $\mathrm{Fe}_{3} \mathrm{O}_{4}, \mathrm{Fe}_{3} \mathrm{O}_{4} @ \mathrm{SiO}_{2}$, and $\mathrm{Fe}_{3} \mathrm{O}_{4} @ \mathrm{SiO}_{2} @ \mathrm{PAA}$ were used as shown in Fig. 1C. Compared with $\mathrm{Fe}_{3} \mathrm{O}_{4}$, a single characteristic peak at $2 \theta \approx 22^{\circ}$ was displayed in the diffraction peaks of $\mathrm{Fe}_{3} \mathrm{O}_{4} @ \mathrm{SiO}_{2}$ and $\mathrm{Fe}_{3} \mathrm{O}_{4} @ \mathrm{SiO}_{2} @ \mathrm{PAA}$. The results revealed that $\mathrm{SiO}_{2}$ was successfully grafted onto the $\mathrm{Fe}_{3} \mathrm{O}_{4}$ surface and that the amorphous layer did not impact the structure of $\mathrm{Fe}_{3} \mathrm{O}_{4} \cdot{ }^{42}$ The magnetism was analyzed using a magnetometer at room temperature; the results are displayed in Fig. 1D. The saturation intensities for $\mathrm{Fe}_{3} \mathrm{O}_{4}, \mathrm{Fe}_{3} \mathrm{O}_{4} @ \mathrm{SiO}_{2}$, and $\mathrm{Fe}_{3} \mathrm{O}_{4} @ \mathrm{SiO}_{2} @ \mathrm{PAA}$ were 57.168, 18.234, and 18.164 emu $\mathrm{g}^{-1}$, respectively. This difference was possibly due to the introduction of silica shells to the surface of $\mathrm{Fe}_{3} \mathrm{O}_{4}$ nanoparticles, which decreased magneticity. Thus, these observations confirm that we were able to obtain $\mathrm{Fe}_{3} \mathrm{O}_{4} @ \mathrm{SiO}_{2} @ \mathrm{PAA}$ possessing the desired properties.

To amplify signal for low concentration target sIgE, HMNs were prepared using the soft template method..$^{43}$ Briefly, silicon source was coated on the surface of template PS during a condensation polymerization, after which calcination decomposition of the PS was performed to form HMNs. The synthesized materials were characterized with TEM and FTIR. TEM images showed that the PS nanospheres had round, 

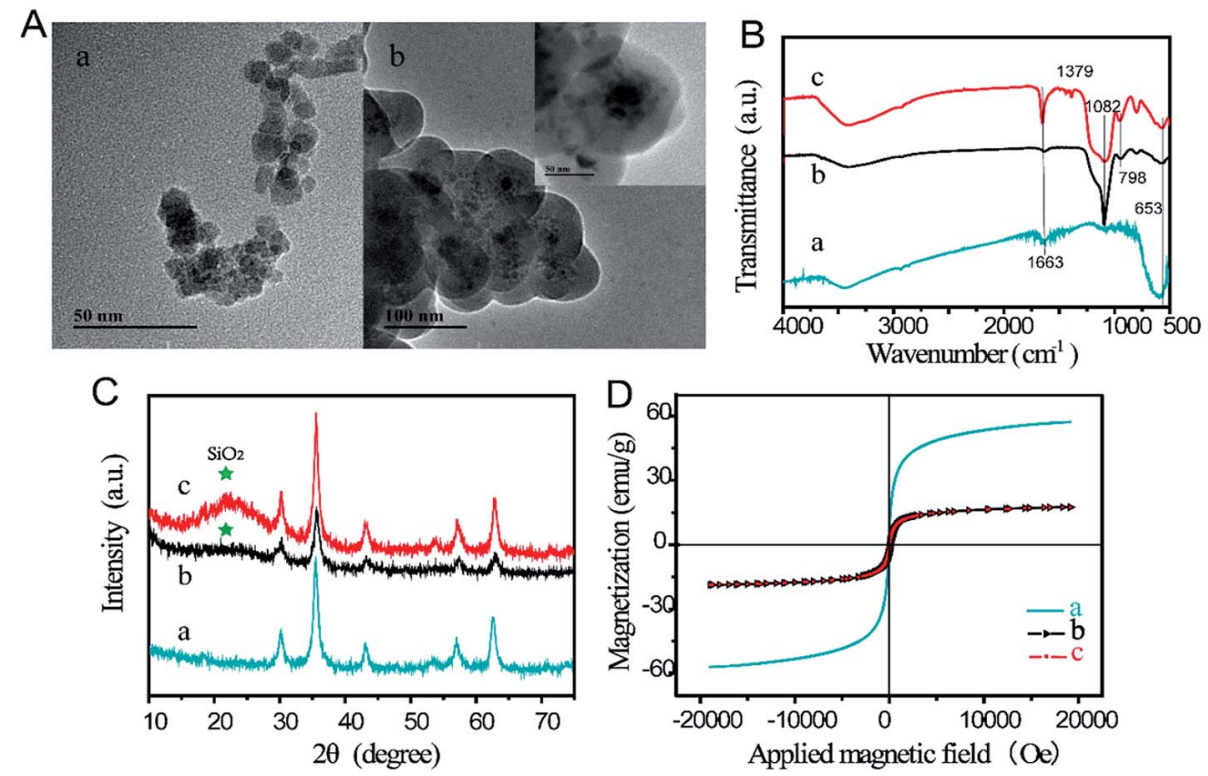

Fig. 1 (A) TEM images of $\mathrm{Fe}_{3} \mathrm{O}_{4}$ (a) and $\mathrm{Fe}_{3} \mathrm{O}_{4} \mathrm{aSiO}_{2}$ (b); (B) FTIR images; (C) XRD images; and (D) magnetic intensity images of Fe $\mathrm{O}_{4}$, (b) $\mathrm{Fe}_{3} \mathrm{O}_{4} \mathrm{CSiO}_{2}$, and (c) $\mathrm{Fe}_{3} \mathrm{O}_{4} \mathrm{aSiO}_{2}(\mathrm{aPAA}$.

uniform structures with an average diameter of $130 \mathrm{~nm}$ as shown in Fig. 2A. Fig. 2B indicates that the hollow structures possessed a mesoporous $\mathrm{SiO}_{2}$ spherical shell with $35 \mathrm{~nm}$ thickness. The unique hollow structure and grouping of the HMNs suggest them as attractive candidates for dye molecules. The FTIR of HMNs, FITC, and FHMNs@polymers are shown in Fig. 2C. With the accumulation of FITC molecules and selfassembly of PDDA and PAA, the peaks at 1732 and $1390 \mathrm{~cm}^{-1}$ could be ascribed to the $\mathrm{C}=\mathrm{O}$ stretch vibration and $\mathrm{O}-\mathrm{H}$ of the $\mathrm{C}-\mathrm{O}-\mathrm{H}$ group, ${ }^{40,44}$ respectively; additionally, the band of the $\mathrm{C}=\mathrm{C}$ group at $1605 \mathrm{~cm}^{-1}$ increased whereas the band of $\mathrm{Si}-\mathrm{O}-\mathrm{Si}$ at $1082 \mathrm{~cm}^{-1}$ weakened (curve c)..$^{38}$ These data further demonstrate that FHMNs@polymers were successfully achieved.

\section{Optimization of the detection conditions}

The $\mathrm{pH}$ of the fluorescein-release solution, incubation temperature, and incubation time plays important roles in the performance of the sensor. First, the effect of $\mathrm{pH}$ was investigated, which indicated that the fluorescence intensity reached a maximum value just at $\mathrm{pH} 11.0$, as shown in Fig. 3A. In acidic and neutral environments, the dye molecules were protected by an undissolved $\mathrm{SiO}_{2}$ shell and shrunken polymer layers, allowing no fluorescein leakage. In an alkaline solution of sodium hydroxide, the weaker the alkalinity, the longer the time that was needed to release all of the dye molecules. The fluorescence intensity of the released fluorescein was affected by the acidity, this property may occur because of the structure of FITC. Taking both of these factors into account, a sodium hydroxide solution of $\mathrm{pH} 11.0$ was used to release the fluorescein and as the detection medium. In addition, investigation of the effect of incubation temperature determined that the maximal fluorescence intensity was obtained at $37^{\circ} \mathrm{C}$ as shown in Fig. 3B. When the incubation temperature was higher than $37^{\circ} \mathrm{C}$, the intensity of the fluorescence decreased, which may have occurred because of a reduction in biomolecule activity at high temperatures. Investigating the effect of incubation time showed that approximately $85 \%$ of fluorescence intensity was obtained at $60 \mathrm{~min}$, when most of the silica was dissolved and a large number of fluorescent molecules were released. Thus, in order
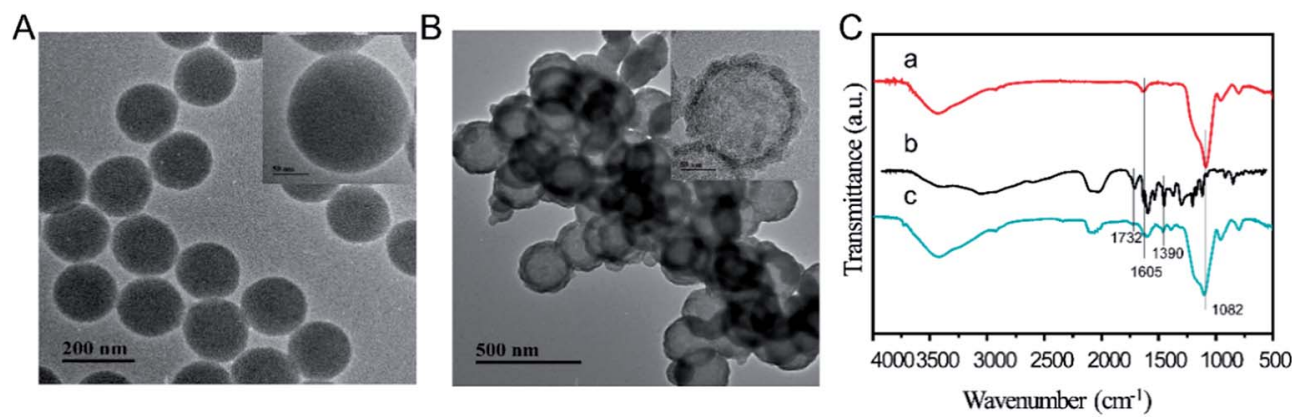

Fig. 2 TEM images of (A) polystyrene nanospheres and (B) HMNs. (C) FTIR of (a) HMNs, (b) FITC, and (c) FHMNs@polymers. 
A

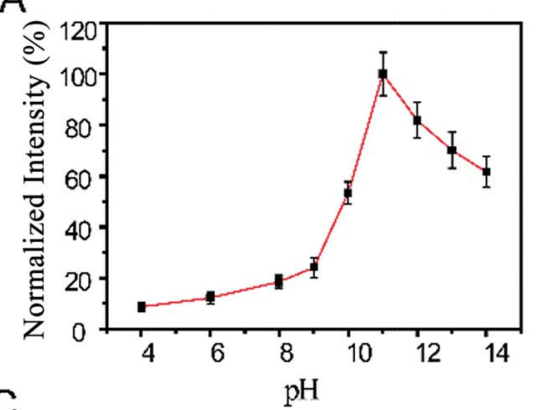

C

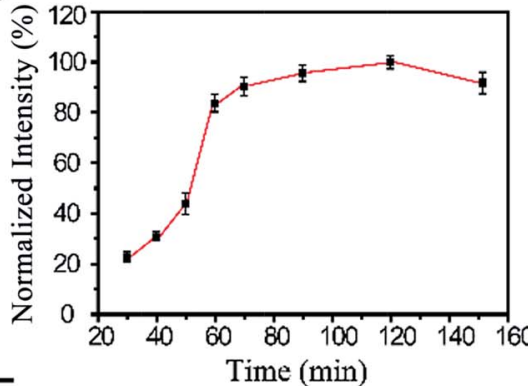

E

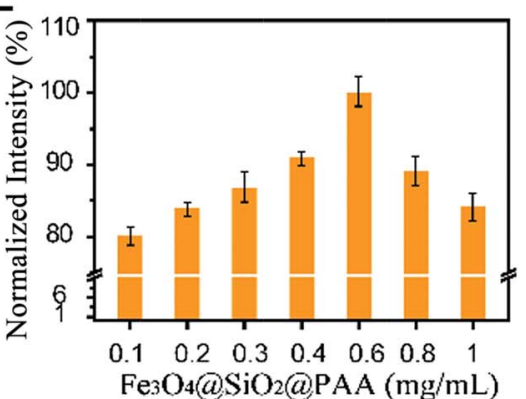

$\mathrm{B}$
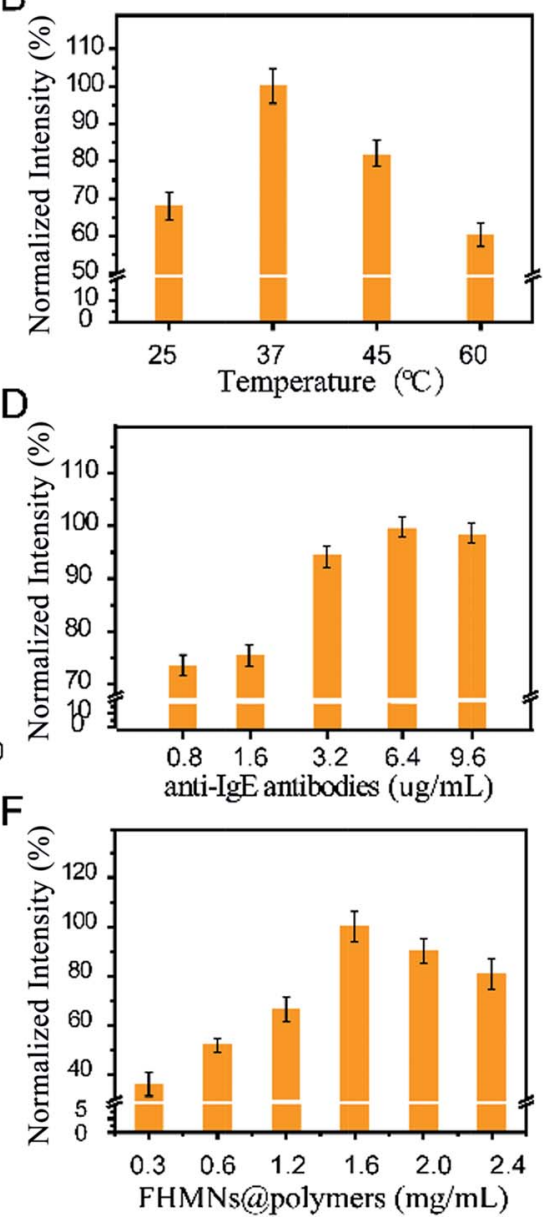

Fig. 3 Effect of $\mathrm{pH}(\mathrm{A})$, incubation time (B), incubation temperature (C), concentration of anti-lgE antibodies (D), concentration of Fe $\mathrm{O}_{4}(\mathrm{a}-$ $\mathrm{SiO}_{2}$ (aPAA (E), and concentration of FHMNs@polymers (F) on fluorescence intensity.

to achieve rapid detection, we adopted 60 min incubation time although subsequently increasing for fluorescence intensity (Fig. 3C). Based the above results, the conditions of $\mathrm{pH} 11.0$, incubation temperature of $37^{\circ} \mathrm{C}$ and incubation time of $60 \mathrm{~min}$ were employed in the subsequent experiments.

The concentrations of anti-IgE antibodies, $\mathrm{Fe}_{3} \mathrm{O}_{4} @ \mathrm{SiO}_{2} @-$ PAA, and FHMNs@polymers were optimized as follows. Investigation of the effect of anti-IgE antibody concentration determined that the maximal fluorescence intensity was obtained at $6.4 \mu \mathrm{g} \mathrm{mL} \mathrm{m}^{-1}$ (Fig. 3D). A low concentration of anti-IgE antibody resulted in lower fluorescence intensity owing to inadequate binding of antibodies, whereas antibody concentration above $6.4 \mu \mathrm{g} \mathrm{mL} \mathrm{m}^{-1}$ could lead to non-specific binding, which may reduce the sensitivity and specificity of the sensor. In addition, investigation of the effect of $\mathrm{Fe}_{3} \mathrm{O}_{4} @ \mathrm{SiO}_{2} @ P A A$ concentration determined that the maximal fluorescence intensity was obtained at $0.6 \mathrm{mg} \mathrm{mL} \mathrm{m}^{-1}$ (Fig. 3E). The fluorescence intensity decreased when the concentration of $\mathrm{Fe}_{3} \mathrm{O}_{4}$ @$\mathrm{SiO}_{2} @ P A A$ was higher than $0.6 \mathrm{mg} \mathrm{mL}^{-1}$ because the excess $\mathrm{Fe}_{3} \mathrm{O}_{4}$ obtained after dissolution of the silica shell produced a quenching effect. ${ }^{45}$ Investigating the effect of FHMNs@polymers concentrations showed that the maximum fluorescence was exhibited at $1.6 \mathrm{mg} \mathrm{mL} \mathrm{m}^{-1}$ (Fig. 3F). The fluorescence intensity was decreased when the amount of FHMNs@polymers was more than $1.6 \mathrm{mg} \mathrm{mL}^{-1}$, which may have been due to the aggregation-induced quenching effect of fluorescence molecules. ${ }^{46}$ In conclusion, the conditions of $6.4 \mu \mathrm{g} \mathrm{mL} \mathrm{m}^{-1}$ anti-IgE, $0.6 \quad \mathrm{mg} \quad \mathrm{mL}^{-1} \quad \mathrm{Fe}_{3} \mathrm{O}_{4} @ \mathrm{SiO}_{2} @ \mathrm{PAA}$, and $1.6 \mathrm{mg} \mathrm{mL}^{-1}$ FHMNs@polymers were employed in the subsequent experiments.

\section{Working principles of the sensor}

Scheme 1 illustrates the preparation of the EMFP sensor and the working principle of the sensor for detecting and quantifying the target sIgE. The synthesized $\mathrm{Fe}_{3} \mathrm{O}_{4} @ \mathrm{SiO}_{2} @ P A A$ carried purified allergens $(\mathrm{Ag})$, which captured and separated target sIgEs in a one-step process. In addition, thousands of fluorescein molecules encapsulated in individual protective HMNs along with anti-IgE antibody linked to FHMNs@polymers, together provided a highly amplified signal for fluorescencebased bio-analysis, as the two immune nanocomposites were linked with target sIgEs and functioned simultaneously. These constitute an ideal candidate platform to amplify the signal of low level sIgE and provide rapid enrichment and separation of 


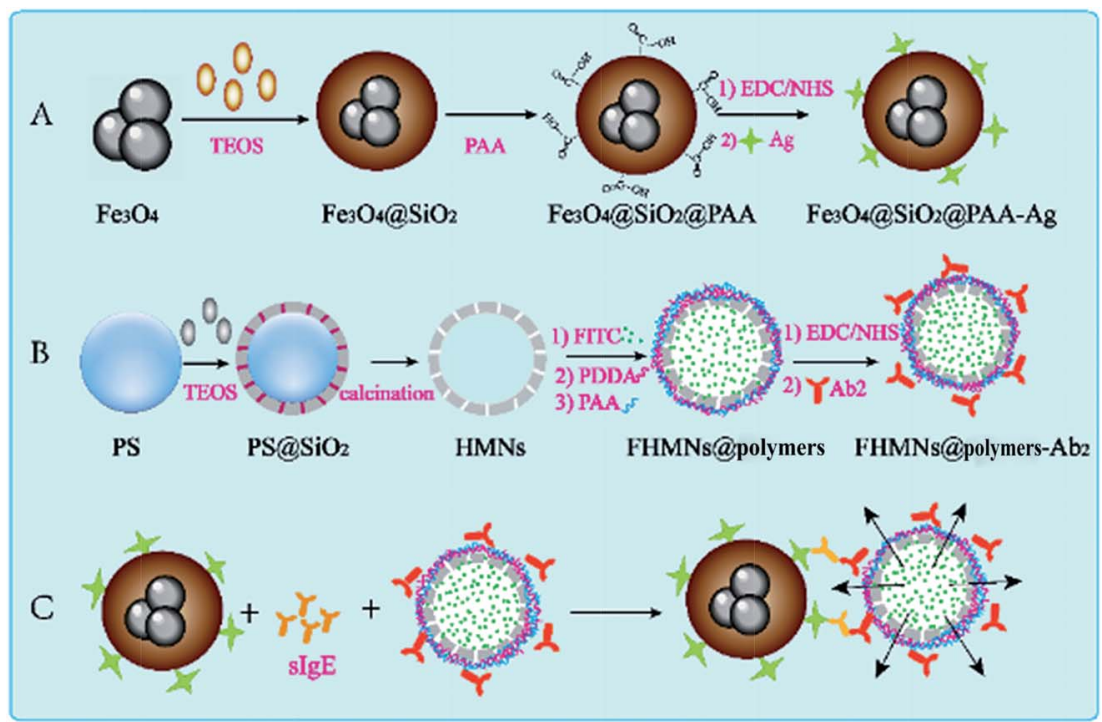

Scheme 1 Schematic of (A) the preparation of magnetic immune probes, (B) the preparation of FHMNs(apolymer-Ab 2 , and (C) the bioassay procedure for target slgE detection.

target sIgE. Moreover, it is a simple procedure because the conjugation between allergen and antibody requires only one step, and non-specific antibody is separated and removed by only one wash procedure repeated five times. This straightforward assay results in rapid detection and high sensitivity for the target sIgE.
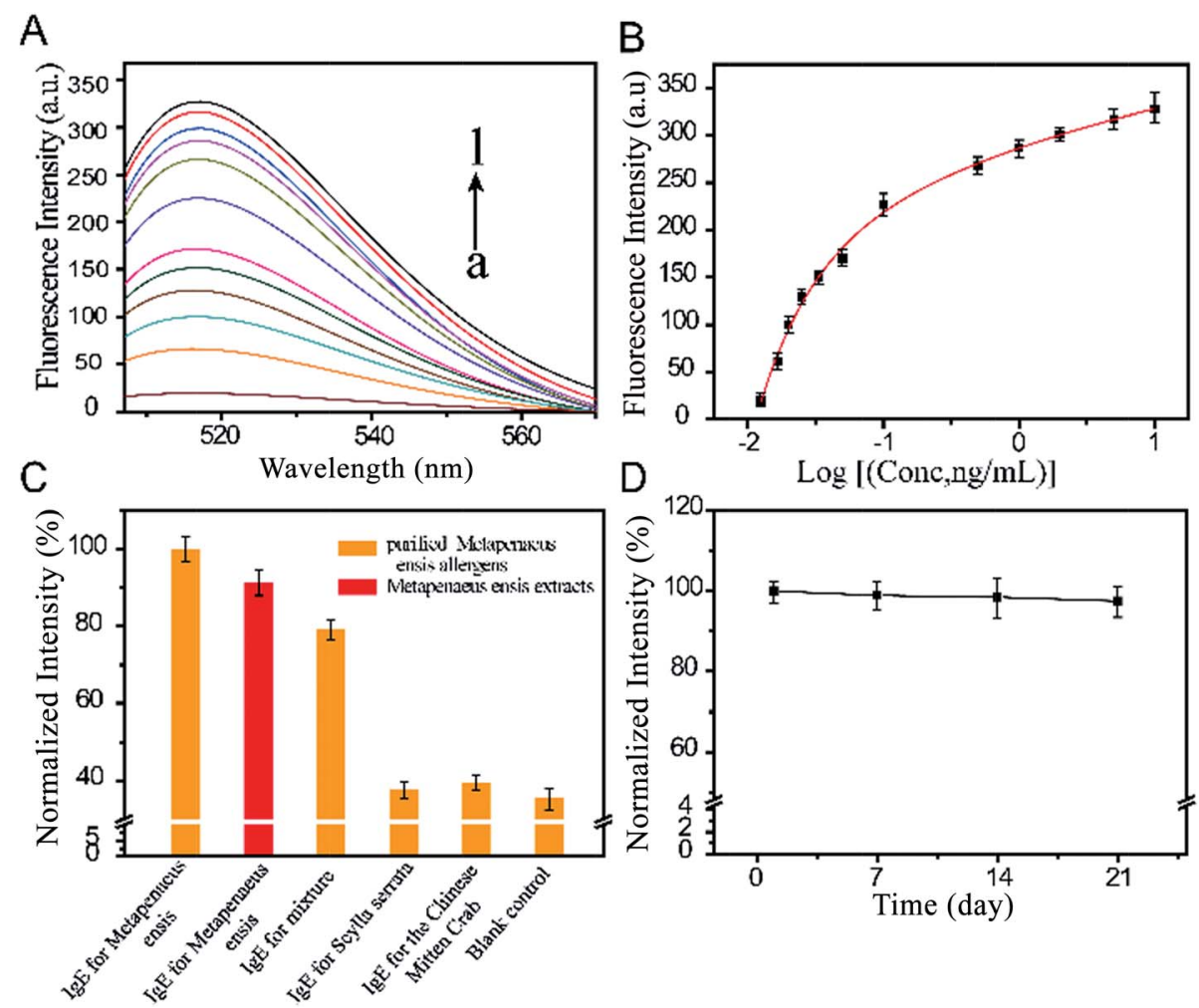

Fig. 4 Characterization of the fluorescent responses of the sensor using slgE. (A) Fluorescent responses of the sensor using different concentrations of slgE of Meta. E. (a) $0.0125 \mathrm{ng} \mathrm{mL}^{-1}$, (b) $0.0159 \mathrm{ng} \mathrm{mL}^{-1}$, (c) $0.02 \mathrm{ng} \mathrm{mL}^{-1}$, (d) $0.025 \mathrm{ng} \mathrm{mL}^{-1}$, (e) $0.03333 \mathrm{ng} \mathrm{mL}^{-1}$, (f) $0.05 \mathrm{ng}$ $\mathrm{mL}^{-1}$, (g) $0.10 \mathrm{ng} \mathrm{mL}^{-1}$, (h) $0.50 \mathrm{ng} \mathrm{mL}^{-1}$, (i) $1 \mathrm{ng} \mathrm{mL}^{-1}$, (j) $2 \mathrm{ng} \mathrm{mL}^{-1}$, (k) $5 \mathrm{ng} \mathrm{mL}^{-1}$, (l) $9.895 \mathrm{ng} \mathrm{mL}^{-1}$. (B) The corresponding calibration curve between fluorescent values of released FHMNs and the concentration of slgE of Meta. E. (other assay conditions were optimized). (C) Fluorescent responses of the sensor in a variety of different sera with purified and crude allergens: slgE antibodies for Meta. E., Scylla serrata, the Chinese mitten crab, and a mixture of slgEs for these. (D) Fluorescent responses of the sensor by storage time at $4{ }^{\circ} \mathrm{C}$. 


\section{Sensitivity, selectivity, and stability of the sensor}

In order to estimate the sensitivity of the sensor, a dose response study was performed with different concentrations of human sera. It can be seen in Fig. 4A that fluorescence intensity (excitation at $517 \mathrm{~nm}$ ) gradually increased with growing concentration of target SIgE. As shown in Fig. 4B, the fluorescence intensity and concentrations of target SIgE had a correlation coefficient of 0.9959 . The good linear relationship ranging from 0.0125 to $9.895 \mathrm{ng} \mathrm{mL} \mathrm{m}^{-1}$, could be expressed by the regression equation $y=452-164.2 \times 0.7562^{x}-1.387 \times$ $0.0842^{x}$. This indicated that the fluorescent sensor could be employed to quantize the concentration of the target sIgE. The limit of detection (LOD) (three times the standard deviation above the blank, $n=6$ ) of the sensor was as low as $0.0159 \mathrm{ng}$ $\mathrm{mL}^{-1}$, this is lower than the lowest detectable concentration of $0.24 \mathrm{ng} \mathrm{mL} \mathrm{m}^{-1}$ measured by the ImmunoCAP system. The results thus indicate that the sensor is highly sensitive for target sIgEs.

To verify the selectivity of the method, sIgEs was employed including sIgE of Meta. E., the Chinese mitten crab, Scylla serrata, and a mixture of SIgE of those with the same concentrations. As shown in Fig. 4C, compared to the blank test, the fluorescence intensity for the presence of the control SIgE (for the Chinese mitten crab and Scylla serrata) showed negligible changes, whereas that of the mixture containing target sIgE showed a slight influence compared to the target sIgE. In comparison, purified antigens had higher fluorescence intensities than Meta. E. extract, which demonstrates that purified allergens exhibit stronger binding capacity. These results demonstrated that the proposed sensor showed high selectivity toward SIgE against purified Meta. E. antigens.

Stability was tested by examining the fluorescent signal of the sensor against storage time (Fig. 4D). The fluorescent signal changed only slightly when the bio-conjugated FHMNs and magnetic probes were used after storage at $4{ }^{\circ} \mathrm{C}$ for 3 weeks, suggesting the good stability of the sensor, which could be attributed to the well-known biocompatibility of the surface microenvironment for antibody conjugation.

\section{Application of the sensor}

To assess the applicability of the sensor, we tested 9 human sera using both ELISA kits and the developed EMFP system. The results are recorded in Table 1. All samples demonstrated higher level by the EMFP system. Notably, the sIgE in serum \#6 was only detectable by the EMFP system. These results confirm that the sensor possessed high sensitivity. It also showed good repeatability, because the relative standard deviation (RSD) was between $2.560 \%$ and $4.290 \%$ for the EMFP system. In order to highlight the performance of the sensor established in this study, a comparison of $\mathrm{IgE}$ detection sensors according to their analytical performances was conducted, as shown in Table 2. The total assay time for the system was $75 \mathrm{~min}$ in this study (60 min for immunomagnetic separation, and $15 \mathrm{~min}$ for release and measurement), which is superior to most detection times except for at $30 \mathrm{~min}$, whereas the limit of detection of $0.0159 \mathrm{ng} \mathrm{mL}^{-1}$ in the present study is the best among the reviewed studies. ${ }^{23,25,26,28,30,45-47}$ In particular, one article used a similar
Table 1 slgE antibody concentrations from nine serum samples as measured by ELISA kits and the EMFP system ${ }^{a}$

\begin{tabular}{|c|c|c|c|c|}
\hline \multirow[b]{2}{*}{ Serum number } & \multicolumn{2}{|c|}{$\begin{array}{l}\text { Commercial ELISA kit } \\
\text { value }\end{array}$} & \multicolumn{2}{|c|}{ EMFP system value $^{b}$} \\
\hline & $\left(\mathrm{ng} \mathrm{mL}^{-1}\right)$ & RSD (\%) & $\left(\mathrm{ng} \mathrm{mL}^{-1}\right)$ & RSD (\%) \\
\hline 1 & 1.997 & 4.952 & 2.193 & 3.466 \\
\hline 2 & 3.228 & 3.934 & 4.128 & 3.506 \\
\hline 3 & 4.034 & 2.333 & 5.221 & 4.290 \\
\hline 4 & 5.723 & 3.390 & 6.518 & 2.946 \\
\hline 5 & BLOD & - & BLOD & - \\
\hline 6 & BLOD & - & 0.092 & 2.348 \\
\hline 7 & 6.613 & 3.160 & 7.148 & 2.560 \\
\hline 8 & 5.113 & 4.049 & 5.726 & 2.655 \\
\hline 9 & 8.476 & 4.567 & 9.216 & 2.717 \\
\hline
\end{tabular}

${ }^{a}$ BLOD means the concentration of SIgE for Meta. E. is below the LOD.

${ }^{b}$ Calculated value using the logistic function above.

Table 2 Comparison of the analytical parameters for IgE detection obtained in this study and reported by previous studies ${ }^{a}$

\begin{tabular}{|c|c|c|c|c|}
\hline Detection method & Labels & $\begin{array}{l}\text { LOD } \\
\left(\mathrm{ng} \mathrm{mL}^{-1}\right)\end{array}$ & $\begin{array}{l}\text { Detection } \\
\text { period } \\
(\mathrm{min})\end{array}$ & Reference \\
\hline Radioimmunometric & Isotope & 0.05 & & 26 \\
\hline ImmunoCAP ISAC & HRP & 0.24 & 150 & 23 \\
\hline Fluorescent & $\begin{array}{l}\text { Photonic } \\
\text { crystal }\end{array}$ & 0.048 & & 48 \\
\hline Fluorescent & $\begin{array}{l}\text { Gold } \\
\text { nanoparticles }\end{array}$ & 0.2 & 270 & 28 \\
\hline Chemiluminescent & HRP & 300 & 240 & 47 \\
\hline Nanoplasmonic & Gold nanodisk & 0.6 & 30 & 49 \\
\hline Fluorescent & Streptavidin & 60 & 150 & 47 \\
\hline Electrochemical & Aptamers & $>300$ & & 50 \\
\hline Fluorescent & FHMNs & 0.0159 & 75 & This work \\
\hline
\end{tabular}

strategy whereby fluorescent microspheres were used as carriers to capture IgE and simultaneously quantify the concentration of IgE. ${ }^{47}$ In contrast, in the present study, fluorescent hollow mesoporous nanospheres were utilized to amplify signal from the target IgE in addition to magnetic nanoparticles to rapidly capture and separate the targeted IgE. Moreover, although the previous study applied a fluorescent suspension array to simultaneously detect total $\mathrm{IgE}$ and specific $\mathrm{IgE}$, this required substantial time because of the tedious steps. Moreover, the sensitivity was less than that of the EMFP, owing to the high efficiency of EMFP for separation and enrichment of the target SIgE via a one-step process, which also markedly simplified the operation and considerably shortened the reaction time. Together, these results indicate that the sensor has high potential for sensitive, reproducible, rapid, and low-cost detection that is simple to process for the determination of sIgE in human sera.

\section{Conclusion}

In this study, bio-conjugated FHMNs were developed with the function of signal amplification, and magnetic particles were 
synthesized to separate and enrich target sIgE in one step. The sensor composed of these materials was first developed to sensitively test SIgE of Meta. E. from 0.0125 to $9.895 \mathrm{ng} \mathrm{mL}^{-1}$ with a LOD of $0.0159 \mathrm{ng} \mathrm{mL} \mathrm{m}^{-1}$, which is 15 -fold more sensitive than that of the FDA-approved ImmunoCAP analyzers. The sensor also exhibits high sensitivity compared with the commercial ELISA; the deviation of sIgE detection levels between these systems might be attributed to the differences in allergen activity after binding, surface chemistry, fluorescence reporter, and detection instrument. In addition, the analytic process of the EMFP system can be completed within $75 \mathrm{~min}$, which is better than the $240 \mathrm{~min}$ minimum required for ELISA systems, which might be due to the efficient separation and enrichment of the target SIgE in one step effected by the magnetic nanoparticles, and the simplification of the experimental procedure making it easy to handle. Furthermore, the cheaper materials, reagents, and economical detection equipment renders this system more affordable for developing nations. This methodology could also be readily adapted for detecting other allergies by using different allergen-specific bioelements. The application of nanomaterials to immune detection thus has considerable significance for medical development.

\section{Conflicts of interest}

There are no conflicts of interest to declare.

\section{Acknowledgements}

This work was financially supported by Science and Technology Development Fund of Wuxi city (CLE01N1412), the Fundamental Research Funds for the Central Universities (JUSRP51709A), and the Social Development Project of Jiangsu Province (BE2015307). The authors show their gratitude to "Food Science and Technology National Key Laboratory Analysis and Testing Center".

\section{References}

1 G. du Toit, T. Tsakok, S. Lack and G. Lack, J. Allergy Clin. Immunol., 2016, 137, 998-1010.

2 K. J. Allen and J. J. Koplin, Immunol. Allergy Clin. North Am., 2012, 32, 35.

3 A. Muraro, T. Werfel, K. Hoffmann-Sommergruber, G. Roberts, K. Beyer, C. Bindslev-Jensen, V. Cardona, A. Dubois, G. duToit, P. Eigenmann, M. Fernandez Rivas, S. Halken, L. Hickstein, A. Host, E. Knol, G. Lack, M. J. Marchisotto, B. Niggemann, B. I. Nwaru, N. G. Papadopoulos, L. K. Poulsen, A. F. Santos, I. Skypala, A. Schoepfer, R. Van Ree, C. Venter, M. Worm, B. VliegBoerstra, S. Panesar, D. de Silva, K. Soares-Weiser, A. Sheikh, B. K. Ballmer-Weber, C. Nilsson, N. W. de Jong, C. A. Akdis and E. F. A. Anaphylaxis, Allergy, 2014, 69, 1008-1025.

4 S. H. Sicherer and H. A. Sampson, J. Allergy Clin. Immunol., 2014, 133, 291.
5 B. I. Nwaru, L. Hickstein, S. S. Panesar, A. Muraro, T. Werfel, V. Cardona, A. E. J. Dubois, S. Halken, K. HoffmannSommergruber, L. K. Poulsen, G. Roberts, R. Van Ree, B. J. Vlieg-Boerstra, A. Sheikh and E. F. A. A. Gui, Allergy, 2014, 69, 62-75.

6 R. J. Rona, T. Keil, C. Summers, D. Gislason, L. Zuidmeer, E. Sodergren, S. T. Sigurdardottir, T. Lindner, K. Goldhahn, J. Dahlstrom, D. McBride and C. Madsen, J. Allergy Clin. Immunol., 2007, 120, 638-646.

7 C. L. Gray, Curr. Allergy Asthma Rep., 2017, 17, 35.

8 L. Polloni, A. DunnGalvin, E. Ferruzza, R. Bonaguro, F. Lazzarotto, A. Toniolo, N. Celegato and A. Muraro, Allergy, 2017, 72, 1054-1060.

9 J. A. Lieberman and S. H. Sicherer, Curr. Allergy Asthma Rep., 2011, 11, 58-64.

10 I. Randhawa, C. P. Parrish and T. Morphew, J. Allergy Clin. Immunol., 2016, 137, AB399.

11 S. H. Sicherer, R. A. Wood and I. Section Allergy, Pediatrics, 2012, 129, 193-197.

12 S. Wahyuni, R. Van Ree, A. Mangali, T. Supali, M. Yazdanbakhsh and E. Sartono, Parasite Immunol., 2003, 25, 609-614.

13 D. Ferastraoaru, M. Shtessel, E. Lobell, G. Hudes, D. Rosenstreich and G. de Vos, Am. J. Rhinol. Allergy, 2017, 8, 53-62.

14 S. J. Galli and M. Tsai, Nat. Med., 2012, 18, 693-704.

15 E. S. Unal, U. Gul, A. B. Dursun and F. Oner Erkekol, Turk. J. Med. Sci., 2017, 47, 577-582.

16 P. J. Howanitz, Arch. Pathol. Lab. Med., 2005, 129, 1252-1261.

17 P. C. Turkeltaub and P. J. Gergen, J. Allergy Clin. Immunol., 1989, 84, 886-890.

18 M. L. Kowalski, I. Ansotegui, W. Aberer, M. Al-Ahmad, M. Akdis, B. K. Ballmer-Weber, K. Beyer, M. Blanca, S. Brown, C. Bunnag, A. C. Hulett, M. Castells, H. H. Chng, F. De Blay, M. Ebisawa, S. Fineman, D. B. K. Golden, T. Haahtela, M. Kaliner, C. Katelaris, B. W. Lee, J. Makowska, U. Muller, J. Mullol, J. Oppenheimer, H.-S. Park, J. Parkerson, G. Passalacqua, R. Pawankar, H. Renz, F. Rueff, M. Sanchez-Borges, J. Sastre, G. Scadding, S. Sicherer, P. Tantilipikorn, J. Tracy, V. van Kempen, B. Bohle, G. W. Canonica, L. Caraballo, M. Gomez, K. Ito, E. Jensen-Jarolim, M. Larche, G. Melioli, L. K. Poulsen, R. Valenta and T. Zuberbier, World Allergy Organ. J., 2016, 9, 33.

19 U. Pipkorn, A. Hammarlund and L. Enerback, Clin. Exp. Allergy, 1989, 19, 19-25.

20 H. A. Sampson and D. G. Ho, J. Allergy Clin. Immunol., 1997, 100, 444-451.

21 M. Yazdanbakhsh, P. G. Kremsner and R. van Ree, Science, 2002, 296, 490-494.

22 I. J. Wang, W. J. J. Karmaus and C.-C. Yang, J. Exposure Sci. Environ. Epidemiol., 2017, 27, 478-483.

23 R. G. Hamilton and P. B. Williams, E. T. T. F. Specific Ig and A. Amer Coll, J. Allergy Clin. Immunol., 2010, 126, 33-38.

24 K. W. Lee, K. Blankenship, B. McKinney, G. Kern, J. Buch, J. Greenwood, P. Brazis, L. Drouet, C. Tambone, R. Faas and G. Weaver, J. Vet. Diagn. Invest., 2015, 27, 461-469. 
25 E. E. Morgan, W. H. Miller Jr and B. Wagner, Vet. Immunol. Immunopathol., 2007, 120, 160-167.

26 L. K. Poulsen, H. J. Malling, I. Sondergaard and B. Weeke, J. Immunol. Methods, 1986, 92, 131-136.

27 D. Jiang, P. Zhu, H. Jiang, J. Ji, X. Sun, W. Gu and G. Zhang, Biosens. Bioelectron., 2015, 70, 482-490.

28 M. Cruz Alonso, L. Trapiella-Alfonso, J. M. Costa Fernandez, R. Pereiro and A. Sanz-Medel, Biosens. Bioelectron., 2016, 77, 1055-1061.

29 E. Ng, K. C. Nadeau and S. X. Wang, Biosens. Bioelectron., 2016, 80, 359-365.

30 Y. Tan, J. F. Halsey, T. Tang, S. Vande Weteringc, E. Taine, M. Van Cleve and B. T. Cunningham, Biosens. Bioelectron., 2016, 77, 194-201.

31 I. Moneo, N. Carballeda-Sangiao and M. Gonzalez-Munoz, Curr. Allergy Asthma Rep., 2017, 17, 27.

32 M. Ben-Shoshan, D. W. Harrington, L. Soller, J. Fragapane, L. Joseph, Y. St Pierre, S. B. Godefroy, S. J. Elliot and A. E. Clarke, J. Allergy Clin. Immunol., 2010, 125, 1327-1335.

33 S. Tsabouri, M. Triga, M. Makris, D. Kalogeromitros, M. K. Church and K. N. Priftis, Pediatr. Allergy Immunol., 2012, 23, 608-615.

34 G. Qi, Y. Wang, L. Estevez, A. K. Switzer, X. Duan, X. Yang and E. P. Giannelis, Chem. Mater., 2010, 22, 2693-2695.

35 R. Cui, C. Liu, J. Shen, D. Gao, J.-J. Zhu and H.-Y. Chen, Adv. Funct. Mater., 2008, 18, 2197-2204.

36 M. L. Kang, J.-Y. Ko, J. E. Kim and G.-I. Im, Biomaterials, 2014, 35, 9984-9994.

37 R.-R. Hu, Z.-Z. Yin, Y.-B. Zeng, J. Zhang, H.-Q. Liu, Y. Shao, S.-B. Ren and L. Li, Biosens. Bioelectron., 2016, 78, 31-36.
38 Q. Dang Viet, J. E. Lee, J.-K. Kim, Y. N. Kim, G. N. Shao and H. T. Kim, Powder Technol., 2013, 235, 221-227.

39 J.-L. Gong, X.-Y. Wang, G.-M. Zeng, L. Chen, J.-H. Deng, X.-R. Zhang and Q.-Y. Niu, Chem. Eng. J., 2012, 185, 100-107.

40 J. Li, Q. Li, Y. Zeng, T. Tang, Y. Pan and L. Li, RSC Adv., 2015, 5, 717-725.

41 B. Fotoohi and L. Mercier, Hydrometallurgy, 2015, 156, 2839.

42 R. El-kharrag, A. M. R. Amin and Y. E. Greish, Ceram. Int., 2012, 38, 627-634.

43 G. Qi, Y. Wang, L. Estevez, A. K. Switzer, X. Duan, X. Yang and E. P. Giannelis, Chem. Mater., 2010, 22, 2693-2695.

44 H. J. Chen, Y. L. Wang, Y. Z. Wang, S. J. Dong and E. K. Wang, Polymer, 2006, 47, 763-766.

45 G. Wang, X. Su, S. Yang, Y. Jia and D. Li, J. Lumin., 2012, 132, 2505-2511.

46 X. Wang, P. Wang, R. Fan, M. Xu, L. Qiang, L. Wei, Y. Yang and Y. Wang, Dalton Trans., 2015, 44, 5179-5190.

47 E. M. King, L. D. Vailes, A. Tsay, S. M. Satinover and M. D. Chapman, J. Allergy Clin. Immunol., 2007, 120, 11261131.

48 Y. F. Tan, J. F. Halsey, T. T. Tang, S. Vande Weteringc, E. Taine, M. Van Cleve and B. T. Cunningham, Biosens. Bioelectron., 2016, 77, 194-201.

49 M. Soler, P. Mesa-Antunez, M. Estevez, A. Ruiz-Sanchez, M. Otte, B. Sepulveda, D. Collado, C. Mayorga, M. Torres, E. Perez-Inestrosa and L. Lechuga, Biosens. Bioelectron., 2015, 66, 115-123.

50 K. Papamichael, M. Kreuzer and G. Guilbault, Sens. Actuators, B, 2007, 121, 178-186. 